\title{
Absolute Antioxidant Activity of Five Phenol-Rich Essential Oils
}

\author{
Yafang Guo ${ }^{1}$, Romeo Pizzol ${ }^{1}$, Simone Gabbanini ${ }^{2}{ }^{\circledR}$, Andrea Baschieri ${ }^{3}(0)$, Riccardo Amorati ${ }^{1}$ \\ and Luca Valgimigli $1, *$ (i)
}

1 Department of Chemistry “G. Ciamician”, University of Bologna, Via S. Giacomo 11, 40126 Bologna, Italy; yafang.guo2@unibo.it (Y.G.); romeo.pizzol@studio.unito.it (R.P.); riccardo.amorati@unibo.it (R.A.)

2 Research \& Development-BeC s.r.l., Via C. Monteverdi 49, 47122 Forlì, Italy; laboratorio@bec-natura.com

3 The Institute of Organic Synthesis and Photoreactivity, Consiglio Nazionale delle Ricerche (CNR), Via P. Gobetti 101, 40129 Bologna, Italy; andrea.baschieri@isof.cnr.it

* Correspondence: luca.valgimigli@unibo.it; Tel.: +39-051-2095683

Citation: Guo, Y.; Pizzol, R.;

Gabbanini, S.; Baschieri, A.; Amorati,

R.; Valgimigli, L. Absolute

Antioxidant Activity of Five

Phenol-Rich Essential Oils. Molecules

2021, 26, 5237. https://doi.org/

$10.3390 /$ molecules 26175237

Academic Editor: Kemal Husnu

Can Baser

Received: 7 August 2021

Accepted: 25 August 2021

Published: 29 August 2021

Publisher's Note: MDPI stays neutral with regard to jurisdictional claims in published maps and institutional affiliations.

Copyright: (C) 2021 by the authors. Licensee MDPI, Basel, Switzerland. This article is an open access article distributed under the terms and conditions of the Creative Commons Attribution (CC BY) license (https:// creativecommons.org/licenses/by/ $4.0 /)$.

\begin{abstract}
Essential oils (EOs) have promising antioxidant activities which are gaining interest as natural alternatives to synthetic antioxidants in the food and cosmetic industries. However, quantitative data on chain-breaking activity and on the kinetics of peroxyl radical trapping are missing. Five phenolrich EOs were analyzed by GC-MS and studied by oxygen-uptake kinetics in inhibited controlled autoxidations of reference substrates (cumene and squalene). Terpene-rich Thymus vulgaris (thymol $4 \%$; carvacrol 33.9\%), Origanum vulgare, (thymol 0.4\%; carvacrol 66.2\%) and Satureja hortensis, (thymol $1.7 \%$; carvacrol $46.6 \%)$, had apparent $k_{\text {inh }}\left(30^{\circ} \mathrm{C}, \mathrm{PhCl}\right)$ of $(1.5 \pm 0.3) \times 10^{4},(1.3 \pm 0.1) \times 10^{4}$ and $(1.1 \pm 0.3) \times 10^{4} \mathrm{M}^{-1} \mathrm{~s}^{-1}$, respectively, while phenylpropanoid-rich Eugenia caryophyllus (eugenol 80.8\%) and Cinnamomum zeylanicum, (eugenol $81.4 \%$ ) showed apparent $k_{\text {inh }}\left(30{ }^{\circ} \mathrm{C}, \mathrm{PhCl}\right)$ of $(5.0 \pm 0.1) \times 10^{3}$ and $(4.9 \pm 0.3) \times 10^{3} \mathrm{M}^{-1} \mathrm{~s}^{-1}$, respectively. All EOs already granted good antioxidant protection of cumene at a concentration of $1 \mathrm{ppm}(1 \mathrm{mg} / \mathrm{L})$, the duration being proportional to their phenolic content, which dictated their antioxidant behavior. They also afforded excellent protection of squalene after adjusting their concentration $(100 \mathrm{mg} / \mathrm{L})$ to account for the much higher oxidizability of this substrate. All investigated EOs had $k_{\text {inh }}$ comparable to synthetic butylated hydroxytoluene (BHT) were are eligible to replace it in the protection of food or cosmetic products.
\end{abstract}

Keywords: essential oils; antioxidant; GC-MS; thyme; oregano; savory; clove; cinnamon; peroxyl radicals

\section{Introduction}

Among the many properties that are often attributed to plant essential oils (EOs), the antioxidant property certainly stands out [1]. When paired with the antimicrobial activity, which has been extensively documented for many essential oils in recent and less recent literature [2-4], the additional antioxidant activity makes those natural materials extremely attractive as multi-functional preservatives, e.g., for food products, able to control spoilage caused both by microbial metabolism and by air oxidation [3,5]. In recent years, consumer choice has progressively oriented food technologists toward more natural and (expectedly) safer alternatives to synthetic additives, which has boosted the interest in plant-derived bioactives, including essential oils [1-3,5,6].

On the other hand, essential oils have long-standing traditions of use in several field, ranging from cosmetics to medicine, from the preservation of artistic heritage to veterinary and agriculture applications, and many such uses are based on their purported antioxidant activity [7-14]. Not surprisingly, therefore, several investigations on the antioxidant activity of EOs have appeared in the scientific literature. However, the majority of such studies have only focused on qualitative assessment or have relied on popular assays based on single-point assessment of their reducing ability toward some oxidizing species (e.g., $\mathrm{Fe}^{3+}$ ) or persistent artificial radicals (e.g., DPPH or ABTS) [5]. While these assays can shed light on a potential activity, they cannot provide quantitative absolute descriptors of the antioxidant 
activity [15] —namely, the kinetic constants for trapping peroxyl radicals and breaking the oxidative chain-reaction [16-18] - and their results depend on the experimental settings, making it difficult to compare or rationalize the data $[5,15,18]$. In other cases, studies were based on real-life applications, such as on tests of food spoilage [19-21], which are certainly relevant but often cannot distinguish what is caused by microorganisms and what is caused by air oxidation [5]. These limits have already been discussed in detail [5,15-18]; however, a clear problem arises when trying to overcome them, in that, at variance with single-molecule antioxidants, essential oils are complex mixtures of a few to dozens of components, whose individual contribution to the properties of the whole oil is often unknown.

In this study, we are presenting and testing a simplified approach to deal with this complexity, at least in the case of phenol-rich EOs, which are abundant in nature. Five essential oils from different botanical sources, of very common use in the food industry as well as in the cosmetic and other industries [5], were chosen as representative prototypes of phenol-rich EOs, namely red thyme (Thymus vulgaris, L.), oregano (Origanum vulgare, L.), savory (Satureja hortensis, L.), which is rich in terpenic phenols, clove bud (Eugenia caryophyllus, Spreng. or Syzygium aromaticum, L.), and cinnamon leaves (Cinnamomum zeylanicum, Blume), which is rich in phenylpropanoids. Since there is major variability in the composition of EOs, even within the same botanical species, due to chemotype, climate, soil composition, cultivation technique, plant collection time, and extraction method [22-24], we subjected our specimens to composition analysis prior to studying their reactivity with peroxyl radicals by means of inhibited autoxidation studies [25-27], which represents the gold standard in antioxidant testing $[15,17,18]$.

To our knowledge, this is the first report of the absolute kinetics of the trapping of peroxyl radicals by these essential oils. The results support their reputation as good antioxidants and provide quantitative grounds for their eligibility as replacement for synthetic antioxidants in specific applications.

\section{Results and Discussion}

\subsection{Phenolic Compositions of the Essential Oils}

The composition of the EO specimens used in this study was determined by CGMS analysis. Identification of the components was based on Kovat's Index [28], and on matching the mass spectrum with the NIST (National Institute of Standards and Technology, USA) library [29] and with an internal (self-built) spectral library for essential oils. Chromatograms and details for components' assignment are provided as Supplementary Material, while results are summarized in Table 1 . To simplify the assignment, components with peak area $<0.1 \%$ were not investigated, since our focus was on the antioxidant activity and no significant contribution can reasonably be expected from such minor components under our experimental design, based on testing the essential oils at very low concentrations (see Section 2.2). To gain a more accurate measurement of the relative abundance of components in each oil in the absence of calibration with authentic standards of individual components, we turned to the flame ionization detector (FID) method, since GC-FID normally offers better accuracy and better linear range as compared to GC-MS under these conditions [30]. Although this approach does not offer the same accuracy as true calibration [30], previous experience under identical instrumental settings indicated a variation $\leq 10 \%$ of the relative response factor (RRF expressed as mass ratio) among similar EO components, which was judged sufficient to the scope of our investigation. Therefore, following the identification of components by GC-MS, samples were re-analyzed under identical settings in GC-FID, taking advantage of a combined instrument (see Section 3.2). 
Table 1. Composition of the investigated EOs, identified by CG-MS analysis. Concentrations are expressed as \% peak area ( $\pm \mathrm{SD}, n=3)$ in the chromatogram from GC-FID analysis.

\begin{tabular}{|c|c|c|c|}
\hline EO & $d\left(\mathrm{~g} / \mathrm{mL}, 20^{\circ} \mathrm{C}\right)$ & Component & $\%(p / p)$ \\
\hline \multirow{7}{*}{$\begin{array}{l}\text { T. vulgaris, L. } \\
\text { (thyme) }\end{array}$} & \multirow{7}{*}{0.912} & $\alpha$-Thujene & $1.6 \pm 0.1$ \\
\hline & & $\alpha$-Pinene & $3.8 \pm 0.1$ \\
\hline & & Camphene & $8.6 \pm 0.2$ \\
\hline & & $\beta$-Pinene & $2.6 \pm 0.1$ \\
\hline & & p-Cymene & $45.3 \pm 1.2$ \\
\hline & & Thymol & $4.0 \pm 0.1$ \\
\hline & & Carvacrol & $33.9 \pm 0.7$ \\
\hline \multirow{10}{*}{$\begin{array}{l}\text { O. vulgare, } \mathrm{L} \text {. } \\
\text { (oregano) }\end{array}$} & \multirow{10}{*}{0.948} & $\alpha$-Phellandrene & $0.4 \pm 0.0_{2}$ \\
\hline & & $\alpha$-Pinene & $0.7 \pm 0.1$ \\
\hline & & Myrcene & $1.2 \pm 0.1$ \\
\hline & & $\alpha$-Terpinene & $1.1 \pm 0.1$ \\
\hline & & p-Cymene & $14.1 \pm 0.3$ \\
\hline & & $\gamma$-Terpinene & $4.9 \pm 0.1$ \\
\hline & & Linalool & $2.1 \pm 0.1$ \\
\hline & & Thymol & $0.4 \pm 0.0_{3}$ \\
\hline & & Carvacrol & $69.2 \pm 1.4$ \\
\hline & & $\beta$-Caryophyllene & $1.6 \pm 0.2$ \\
\hline \multirow{16}{*}{$\begin{array}{l}\text { S. hortensis, L. } \\
\text { (savory) }\end{array}$} & \multirow{16}{*}{0.937} & $\alpha$-Pinene & $1.8 \pm 0.1$ \\
\hline & & Camphene & $0.9 \pm 0.1$ \\
\hline & & $\beta$-Pinene & $0.2 \pm 0.0_{2}$ \\
\hline & & Myrcene & $1.3 \pm 0.1$ \\
\hline & & $\alpha$-Terpinene & $2.3 \pm 0.1$ \\
\hline & & p-Cymene & $20.0 \pm 0.8$ \\
\hline & & Limonene & $0.9 \pm 0.0_{4}$ \\
\hline & & Eucalyptol & $0.6 \pm 0.0_{2}$ \\
\hline & & $\gamma$-Terpinene & $17.0 \pm 0.6$ \\
\hline & & Thymol & $1.7 \pm 0.1$ \\
\hline & & Carvacrol & $46.6 \pm 1.7$ \\
\hline & & Thymol Acetate & $0.6 \pm 0.0_{2}$ \\
\hline & & $\beta$-Caryophyllene & $1.6 \pm 0.1$ \\
\hline & & Aromadendrene & $0.9 \pm 0.0_{3}$ \\
\hline & & $\delta$-Cadinene & $0.3 \pm 0.0_{2}$ \\
\hline & & Caryophyllene Oxide & $0.4 \pm 0.0_{2}$ \\
\hline \multirow{4}{*}{$\begin{array}{l}\text { E. caryophyllus, Spreng } \\
\text { (clove bud) }\end{array}$} & \multirow{4}{*}{1.041} & Eugenol & $80.8 \pm 1.7$ \\
\hline & & $\beta$-Caryophyllene & $8.9 \pm 0.5$ \\
\hline & & Humulene & $1.1 \pm 0.2$ \\
\hline & & Eugenyl Acetate & $9.1 \pm 0.6$ \\
\hline \multirow{11}{*}{$\begin{array}{l}\text { C. zeylanicum, Blume } \\
\text { (cinnamon) }\end{array}$} & \multirow{11}{*}{1.043} & $\alpha$-Pinene & $2.7 \pm 0.1$ \\
\hline & & Camphene & $0.8 \pm 0.0_{3}$ \\
\hline & & $\beta$-Pinene & $0.4 \pm 0.0_{2}$ \\
\hline & & $\alpha$-Phellandrene & $1.7 \pm 0.1$ \\
\hline & & p-Cymene & $1.9 \pm 0.1$ \\
\hline & & Linalool & $2.1 \pm 0.2$ \\
\hline & & Eugenol & $81.4 \pm 1.6$ \\
\hline & & $\beta$-Caryophyllene & $4.8 \pm 0.3$ \\
\hline & & Eugenyl Acetate & $3.7 \pm 0.1$ \\
\hline & & Caryophyllene Oxide & $0.2 \pm 0.0_{4}$ \\
\hline & & Benzyl Benzoate & $0.3 \pm 0.0_{4}$ \\
\hline
\end{tabular}

Red thyme allowed for the identification of seven components, accounting for $99.8 \%$ of the total peak area in the chromatogram, which included two phenolic compounds (Figure 1): thymol (4\%) and carvacrol (33.9\%) summing up to $37.9 \%$ of total phenolics. In oregano, carvacrol was the main component $(69.2 \%)$ and thymol was the only other phenolic component we found, albeit at much lower level (0.4\%) summing up to $69.6 \%$ of total phenolics. In savory, we identified 16 components which accounted for $97.1 \%$ of 
total peak area; among them again thymol (1.7\%) and carvacrol (46.6\%) were the only phenolic components, summing up to $48.3 \%$. The predominant content of clove bud oil was based on phenylpropanoids. Among the four identified components, which accounted for $99.9 \%$ of total peak area, eugenol (Figure 1) was the only phenolic component, representing $80.8 \%$ of the oil. Cinnamon leaves EO had a more complex structure, with 11 identified components representing $100 \%$ of the chromatogram area; however, eugenol was the only phenolic component, accounting for $81.4 \%$ the essential oil.

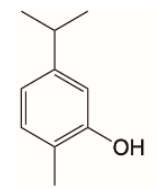

Carvacrol

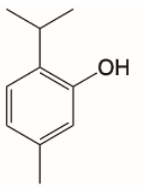

Thymol

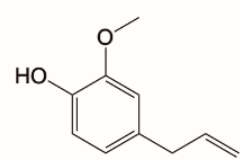

Eugenol

Figure 1. Phenolic components found in the investigated EOs.

Overall, the composition of the investigated EOs was in line with the expected components' range and levels [3] and highlights the presence of only three phenolic components (Figure 1), which represented $38-81 \%$ of the investigated oils, promising a relevant chainbreaking antioxidant activity.

\subsection{Autoxidation of Reference Substrates Inhibited by Essential Oils}

We tested the EOs in the controlled autoxidation of a kinetically characterized oxidizable substrate, which is the best-established approach for quantitative testing $[16,18,31]$. This test was based on monitoring the progress of the autoxidation of a reference substrate by measuring the rate of oxygen consumption in the presence and absence of the test antioxidant. When autoxidation is initiated at a constant rate $R_{\mathrm{i}}$, controlled by the thermal decomposition of an azo-iniziator like 2,2'-azobis(isobutyronitrile) (AIBN), the process can be described by Equations (1)-(6),

$$
\begin{gathered}
\mathrm{R}-\mathrm{N}=\mathrm{N}-\mathrm{R} \rightarrow 2 \mathrm{R} \bullet+\mathrm{N}_{2} \\
\mathrm{R} \bullet+\mathrm{O}_{2} \rightarrow \mathrm{ROO} \bullet \\
\mathrm{RH}+\mathrm{ROO} \bullet \rightarrow \mathrm{R} \bullet+\mathrm{ROOH} \\
2 \mathrm{ROO} \bullet \rightarrow \text { non radical products } \\
\mathrm{AH}+\mathrm{ROO} \bullet \rightarrow \mathrm{A} \bullet+\mathrm{ROOH} \\
\mathrm{A} \bullet+\mathrm{ROO} \bullet \rightarrow \mathrm{ROOA}
\end{gathered}
$$

where $R_{\mathrm{i}}$ is coincident with the rate of reaction 1. Equations (1)-(4) represent the autoxidation of substrate $\mathrm{RH}$ in the absence of antioxidants, while Equations (5) and (6) represent chain-breaking inhibition by antioxidant $\mathrm{AH}$, e.g., a phenolic compound able to transfer the phenolic $\mathrm{O}-\mathrm{H}$ to a chain-carrying peroxyl radical ROO•. Upon reaction with peroxyl radicals (Equation (5)) phenolic antioxidants form stabilized radicals that will normally not propagate the chain, but instead "wait in solution" to trap a second peroxyl radical (Equation (6)). For this reason, phenols are known to have a stoichiometric factor of $n=2$, i.e., each molecule of antioxidant would trap two peroxyl radicals. While this affects primarily the duration of protection, the efficacy of protection depends primarily on $k_{\text {inh }}$, the inhibition rate constant, which is coincident with the rate constant of reaction 5 , being the rate-limiting step of inhibition.

We first tested the five EOs for their ability to inhibit the autoxidation of cumene in chlorobenzene $(\mathrm{PhCl})$ solution, which is among the best-established reference oxidizable substrates [16,32]. All EOs were tested at the very low concentration of $1 \mathrm{mg} / \mathrm{L}$ (1 ppm, $0.0001 \% w / v)$, in order to deconvolute the antioxidant behavior and distinguish chainbreaking inhibition (described by Equations (5) and (6)) from other mechanisms like 
termination-enhancing, previously observed for some EO components [33], which becomes relevant only at rather high concentrations of the antioxidant. The results summarized in Figure 2a show that all tested EOs afforded good protection, giving neat inhibition of the autoxidation for a time $\tau$, which lasted until the antioxidants were consumed, then oxygen consumption restarted at uninhibited rate (see Figure $2 a$, plot d). During the inhibited period, the rate of oxygen consumption is described by Equation (7), where $n$ is the stoichiometric factor ( $n=2$ for phenols, see above) and $k_{\mathrm{p}}$ is the rate constant of oxidative chain propagation, coincident with the rate constant of reaction 3-a specific property of each oxidizable substrate that determines its tendency to oxidize. Since $k_{\mathrm{p}}$ is known for cumene $\left(0.34 \mathrm{M}^{-1} \mathrm{~s}^{-1}\right.$ at $\left.30^{\circ} \mathrm{C}\right)$ [16], and $R_{\mathrm{i}}$ is set in preliminary experiments, fitting the oxygen uptake plots with Equation (7) would afford $k_{\text {inh }}$, i.e., the absolute rate constant for the reaction of the antioxidant with peroxyl radicals (Equation (5)), provided the molar concentration of the substrate $[\mathrm{RH}]$ and of the antioxidant $[\mathrm{AH}]$ are known. Unlike for single-molecule antioxidants, this last provision is not obvious for complex mixtures like EOs. In this study, to make the kinetic analysis tractable, we hypothesized that, to a first approximation, the antioxidant activity arises from the phenolic components in each EOs, all having an expected value of $n=2$. Under this hypothesis, the initial effective concentration $[\mathrm{AH}]_{0}$ can be simply obtained from the duration $(\tau)$ of the inhibited period, according to Equation (8).

$$
\begin{aligned}
-\frac{d[\mathrm{O} 2]}{d t} & =\frac{k_{\mathrm{p}}[\mathrm{RH}] R_{\mathrm{i}}}{n k_{\mathrm{inh}}[\mathrm{AH}]}+R_{\mathrm{i}} \\
R_{\mathrm{i}} & =\frac{n[\mathrm{AH}]_{0}}{\tau}
\end{aligned}
$$

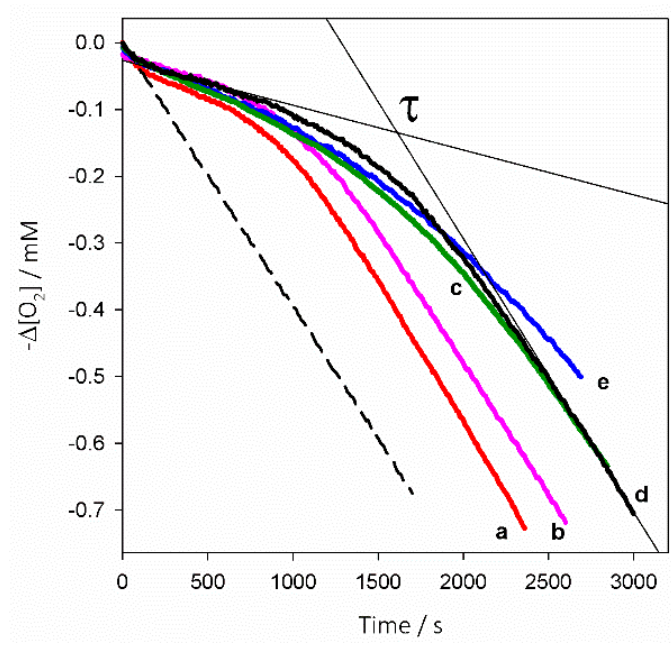

(a)

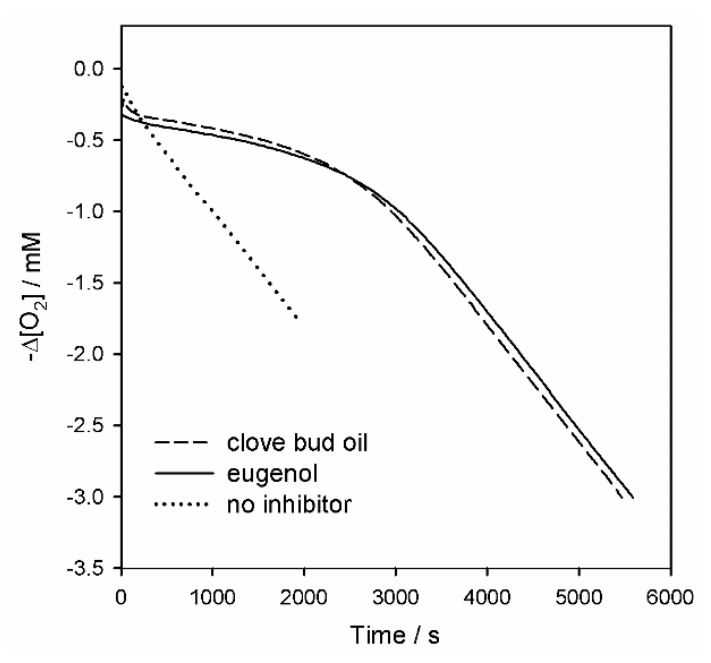

(b)

Figure 2. Oxygen consumption during the autoxidation of cumene (3.6 M) initiated by AIBN $(0.05 \mathrm{M})$ in $\mathrm{PhCl}$ at $30{ }^{\circ} \mathrm{C}$ (panel a) without inhibitors (dashed) or in the presence of EOs (1 mg/L): red thyme (a), savory (b), clove bud (c), oregano (d), cinnamon leaves (e); where inhibition time $\tau$ is determined at the cross-point between inhibited and uninhibited tracts as illustrated for plot (d); and (panel b) without inhibitors (dotted), or in the presence of $1 \mathrm{mg} / \mathrm{L}$ eugenol (full), or clove bud oil (1.25 mg/L) dosed to provide $1 \mathrm{mg} / \mathrm{L}$ eugenol (dashed).

The calculated value of [AH] was then used in Equation (7) to afford the absolute apparent values of $k_{\text {inh }}$ for each tested EO. The results are summarized in Table 2. 
Table 2. Inhibition rate constants at $30^{\circ} \mathrm{C}(\mathrm{PhCl})$ measured for the EOs in the autoxidation of cumene and squalene and apparent concentration of the antioxidant (mean $\pm \mathrm{SD}$ ), matched to the concentration of phenolics estimated from analysis of the EO $(1 \mathrm{mg} / \mathrm{L})$.

\begin{tabular}{|c|c|c|c|c|c|c|}
\hline EO & Phenol & {$\left[\right.$ Phenol]/M ${ }^{1}$} & $\Sigma[$ Phenol $] / \mathbf{M}^{2}$ & {$[\mathrm{AH}]_{\mathrm{app}} / \mathbf{M}^{3}$} & $k_{\text {inh }} / \mathbf{M}^{-1} \mathbf{s}^{-1}$ (cumene) $^{4}$ & $k_{\text {inh }} / \mathbf{M}^{-1} \mathbf{s}^{-1}$ (squalene) $^{5}$ \\
\hline T. vulgaris, L. & $\begin{array}{c}\text { carvacrol } \\
\text { thymol }\end{array}$ & $\begin{array}{l}2.3 \times 10^{-6} \\
2.7 \times 10^{-7}\end{array}$ & $2.6 \times 10^{-6}$ & $(2.5 \pm 0.1) \times 10^{-6}$ & $(1.5 \pm 0.1) \times 10^{4}$ & $(1.0 \pm 0.3) \times 10^{4}$ \\
\hline S. hortensis, L. & $\begin{array}{c}\text { carvacrol } \\
\text { thymol }\end{array}$ & $\begin{array}{l}3.1 \times 10^{-6} \\
1.1 \times 10^{-7} \\
\end{array}$ & $3.2 \times 10^{-6}$ & $(2.9 \pm 0.3) \times 10^{-6}$ & $(1.3 \pm 0.1) \times 10^{4}$ & $(9.8 \pm 1.5) \times 10^{3}$ \\
\hline O. vulgare, L. & $\begin{array}{c}\text { carvacrol } \\
\text { thymol }\end{array}$ & $\begin{array}{l}4.6 \times 10^{-6} \\
0.3 \times 10^{-7} \\
\end{array}$ & $4.6 \times 10^{-6}$ & $(4.8 \pm 0.2) \times 10^{-6}$ & $(1.3 \pm 0.2) \times 10^{4}$ & $(9.5 \pm 0.9) \times 10^{3}$ \\
\hline E. caryophyllus, Spreng & eugenol & $4.9 \times 10^{-6}$ & $4.9 \times 10^{-6}$ & $(4.6 \pm 0.3) \times 10^{-6}$ & $(5.5 \pm 0.5) \times 10^{3}$ & $(5.7 \pm 0.6) \times 10^{3}$ \\
\hline C. zeylanicum, Blume & eugenol & $5.0 \times 10^{-6}$ & $5.0 \times 10^{-6}$ & $(4.4 \pm 0.4) \times 10^{-6}$ & $(4.9 \pm 0.3) \times 10^{3}$ & $(4.8 \pm 0.4) \times 10^{3}$ \\
\hline
\end{tabular}

${ }^{1}$ Estimated from a GC-FID analysis of the EO added to the autoxidizing mixture at $1 \mathrm{mg} / \mathrm{L} .{ }^{2}$ Sum of phenolic components from the EO in the autoxidizing mixture. ${ }^{3}$ Apparent effective concentration of the antioxidant in the mixture of cumene autoxidation, determined from the length of the inhibited period (Equation (8); $\left.[\mathrm{AH}]_{\mathrm{app}}=\left[\mathrm{AH}_{0}\right]\right) .{ }^{4}$ Measured in the inhibited autoxidation of cumene. ${ }^{5}$ Measured in the inhibited autoxidation of squalene.

Values of $k_{\text {inh }}$ for peroxyl radical trapping are disclosed for the first time for the investigated essential oils. Results indicate a clustering of the EOs containing thymol and carvacrol around similar $k_{\text {inh }}$ values $\left(1.3 \times 10^{4}\right.$ to $\left.1.5 \times 10^{4} \mathrm{M}^{-1} \mathrm{~s}^{-1}\right)$, while the two EOs rich in eugenol showed a somewhat lower value around $5 \times 10^{3} \mathrm{M}^{-1} \mathrm{~s}^{-1}$.

These last results can be matched with the previously reported value of $k_{\text {inh }}$ for pure eugenol $\left(4.8 \times 10^{3} \mathrm{M}^{-1} \mathrm{~s}^{-1}\right.$ [34] $)$ to which they are superimposable within experimental error. Although there is no value in the literature for the $k_{\text {inh }}$ of thymol and carvacrol, other structurally related phenols can be taken as reference, e.g., 2,6-dimethylphenol $\left(k_{\text {inh }}=1.5 \times 10^{4} \mathrm{M}^{-1} \mathrm{~s}^{-1}, 30{ }^{\circ} \mathrm{C}, \mathrm{PhCl}\right.$ [16]), bearing two alkyl substituents on the ring, albeit one in a different position. Since alkyl substituents in the ortho position are known to express higher electron donating contributions than in meta, but would also cause higher steric hindrance and the two factors affect the reactivity in opposite directions [16], to a first approximation we can expect both thymol and carvacrol to have $k_{\mathrm{inh}} \sim 1.5 \times 10^{4} \mathrm{M}^{-1} \mathrm{~s}^{-1}$. This value matches the $k_{\text {inh }}$ value measured here for EOs containing the two terpenic phenols. Therefore, it appears that the $k_{\text {inh }}$ for EOs, i.e., their efficiency in trapping peroxyl radicals, largely copies that of the prevailing phenolic component. On the other hand, the duration of antioxidant protection was significantly higher for oregano, clove bud, and cinnamon leaves, as compared to the remaining two oils, as is clearly visible in Figure 2a. This translates into higher values of effective or apparent antioxidant concentration $[\mathrm{AH}]_{\text {app }}$ in the autoxidizing mixture (as determined by Equation (8)), despite the fact that all EOs were used at the same concentration $(1 \mathrm{mg} / \mathrm{L})$.

It is interesting to compare the values of $[\mathrm{AH}]_{\mathrm{app}}$ measured in autoxidations with the estimated molar concentration of EOs phenolic components in the autoxidizing mixture, which were obtained from analysis of the EOs. The estimated total phenolic concentration reported in Table 2 matches the measured effective antioxidant concentration within experimental error, with only cinnamon showing an $[\mathrm{AH}]_{\text {app }}$ value slightly lower that the estimated content of eugenol $(4.4 \pm 0.4 \mu \mathrm{M}$ vs. $5.0 \mu \mathrm{M})$. This minor difference, however, is perfectly justified by the somewhat lower accuracy in determining $\tau$ (see Section 3.3 ) and by the simplicity of our analytical approach, which assumes equal RRF for all EO components, and does not change the main finding: the antioxidant activity of phenol-rich EOs is dictated by their phenolic content, both in terms of efficiency in peroxyl radical trapping and of the duration of the antioxidant protection. As a proof of concept, we performed matched autoxidations of cumene inhibited either by $1 \mathrm{mg} / \mathrm{L}$ of authentic eugenol or by clove bud EO dosed so as to bring the same amount of eugenol to the mixture. As can be seen in Figure $2 b$, the oxygen consumption traces are largely superimposable, confirming our initial hypothesis that the antioxidant activity of phenol-rich EOs arises nearly entirely from their phenolic components. 
While this might seem to be a reasonable finding, it is at odds with some previous reports in the field. For instance, a recent study on the antioxidant activity of cinnamon EO by DPPH and $\mathrm{H}_{2} \mathrm{O}_{2}$ scavenging assays attributed the property to $\alpha$-pinene and sesquiterpenes [35], yet Kaur et al., using the DPPH assay, found that clove bud oil had higher antioxidant activity than eugenol isolated from the oil [36]. Clearly, the major difference between our inhibited autoxidation studies and those assays plays a role in such different outcomes.

In order to confirm our results on a different substrate that would be more challenging to protect and more representative of highly oxidizable food products or ingredients used in cosmetics and pharmaceuticals, we investigated the inhibited autoxidation of squalene. This ubiquitous polyunsaturated triterpenic hydrocarbon composes the unsaponifiable fraction of vegetable oils, particularly of olive, from which it is obtained [37], and it has immune-stimulating bioactivity that makes it interesting as a diet supplement [38] and pharmaceutical ingredient (e.g., in the composition of vaccines) [39], besides being very popular in the cosmetic industry as skin emollient and protectant [37]. Its kinetics of autoxidation was recently characterized in our group highlighting a $k_{\mathrm{p}}$ value of $68 \mathrm{M}^{-1} \mathrm{~s}^{-1}$ $\left(30^{\circ} \mathrm{C}\right)$ [40], i.e., 200-fold faster than cumene, and even faster than linoleic acid, which often taken as prototype for highly oxidizable polyunsaturated lipids [40], which makes its protection quite challenging.

When we tested our EOs with squalene at the concentration of $1 \mathrm{mg} / \mathrm{L}$, no protection was detectable and only on increasing the concentration some slowing down of the oxygen consumption was observed, albeit without a clear inhibition period (see Figure S6 in the Supplementary Material). However, when we raised the concentration to $100 \mathrm{mg} / \mathrm{L}$, to (partly) compensate for the much higher $k_{\mathrm{p}}$ of squalene, excellent protection was granted by all the EOs, as displayed in Figure 3. It should be noted that the increased concentration of EOs in this study corresponds to $0.02 \%(w / v)$ compared to the oxidizable substrate, a value compatible with any technological application and much lower than that typically used for antioxidants in foods or cosmetics (0.1\%).

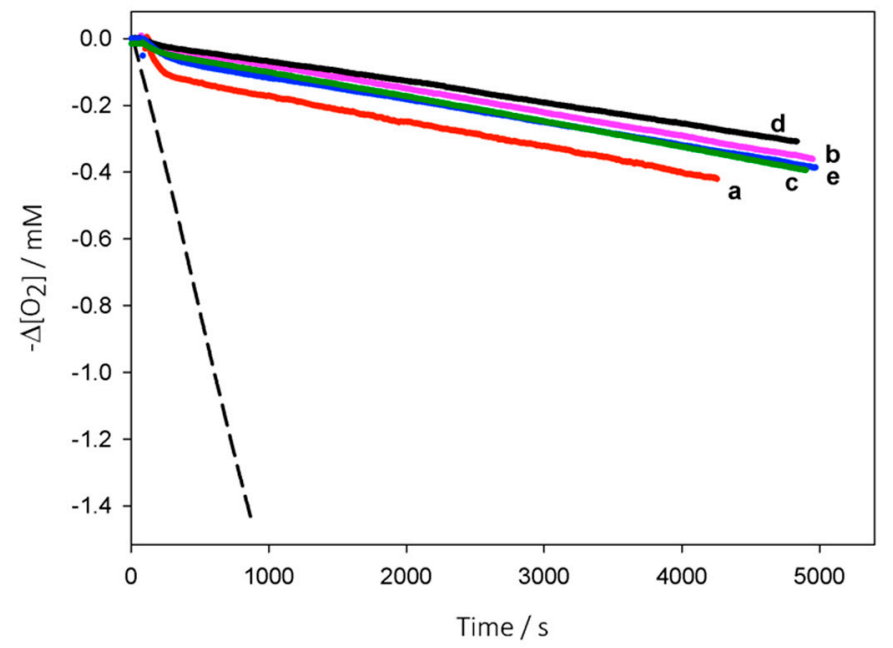

Figure 3. Oxygen consumption during the autoxidation of squalene (1.04 M) initiated by AIBN (0.05 $\mathrm{M})$ in $\mathrm{PhCl}$ at $30{ }^{\circ} \mathrm{C}$ without inhibitors (dashed) or in the presence of $\mathrm{EOs} \mathrm{(100} \mathrm{mg} / \mathrm{L}$ ): red thyme (a), savory (b), clove bud (c), oregano (d), and cinnamon leaves (e).

Analysis of the oxygen consumption traces (Figure 3) was performed better with a different mathematical treatment due to the absence of a visible inhibited period (see Section 3.3), and results were compared to those obtained with cumene in Table 2 . As expected, the $k_{\text {inh }}$ values measured with squalene were very close to those obtained with cumene, when the experimental error and the difference in the analysis method are considered.

It is interesting to note that those values (average of cumene and squalene) are of the same magnitude as the $k_{\text {inh }}$ of the very common antioxidant BHT (butylated hydroxyanisole 
or 2,6-di-tert-butyl-4-methylphenol), reported as $1.0 \times 10^{4} \mathrm{M}^{-1} \mathrm{~s}^{-1}\left(30^{\circ} \mathrm{C}\right)$ [41]; therefore, the investigated EOs afford equivalent antioxidant protection.

\subsection{Study Limitations and Future Directions}

GC-FID analysis with actual calibration, or the use of relative response factors (RRF) calculated for each component brings to higher analytical accuracy [42]. However, our estimation of phenolic EO components (Table 2) from semiquantitative GC-FID, assuming the same mass-based RRF for all components is justified by the proportionality of the FID response factor to the number of carbons in the analyte and was sufficient for the purpose of this investigation under our settings.

One distinctive advantage to our approach, which investigates the chain-braking antioxidant activity of EOs at very low concentration, is that it allows us to deconvolute this most relevant mechanism from artifacts due to the oxidizability of many non-phenolic components, which (at higher concentration) would reduce radicals bringing to misleading results, as was shown to occur with persistent radicals like DPPH, or oxidizing species like $\mathrm{Fe}^{3+}$ or phosphomolibdate used in popular assays, [5]. However, other mechanisms of antioxidant activity by EOs, such as the termination-enhancing mechanism, have been shown to occur at higher concentration due to the chemistry of some non-phenolic components [43]. Testing phenol-poor EOs under different settings would complement our current approach and provide a more complete picture.

A second advantage of the approach used herein is that the autoxidation kinetics were performed at low temperature, thus reducing the loss of volatile components through evaporation. This is clearly an advantage if compared to accelerated oxidation methods based on bubbling a stream of air in heated lipid samples (e.g., lard), in which volatile antioxidant evaporation may explain the limited efficacy of essential oil components [44].

For phenol-rich EOs, our current results offer a relatively simple yet highly reliable means for predicting and rationalizing antioxidant properties based on phenolic composition. However, the approach only tested a limited number of EOs, all containing a limited number of phenolic components. Clearly it would be useful to validate it on a broader and more diverse set of EOs, which we plan to pursue in future work.

\section{Materials and Methods}

\subsection{Materials}

All chemicals and solvents were commercially available (Aldrich-Fluka-Sigma-Merck, Milan, Italy, unless otherwise noted). 2,2'-Azobis(isobutyronitrile) (AIBN) was recrystallized from methanol. 2,2,5,7,8-Pentamethyl-6-chromanol (PMHC) was recrystallized from hexane. Squalene $(\geq 98 \%)$ and cumene $(\geq 98 \%)$ were percolated twice through activated basic alumina and once through silica to remove impurities and traces of hydroperoxides [30,42]. Eugenol (natural, $\geq 98 \%$ ) was used as received. Essential oils of red thyme (T. vulgaris, L.), oregano (O. vulgare, L.), and savory (S. hortensis, L.) were purchased from Maraschi \& Quirici s.p.a. (Riva Presso Chieri, Italy); the EOs of clove bud (E. caryophyllus, Spreng.) and cinnamon leaves (C. zeylanicum, Blume) were from Muller \& Koster s.p.a. (Milano, Italy). All solutions were in chlorobenzene (99.9\% HPLC grade).

\subsection{GC-MS and GC-FID Analysis of the EOs}

GC-MS analysis was carried out on a Star 3400 CX gas chromatograph (Varian, Palo Alto, CA, USA) equipped with a Saturn 2000 ion-trap mass spectrometer detector (Varian), and with a flame ionization detector (FID; $\mathrm{H}_{2}$ / Air), mounting 2 split/splitless 1078 Universal Capillary Injectors (Varian), each leading to a capillary column (Zebron ZB-5, 5\% phenyl-95\% dimethyl-polysiloxane, $30 \mathrm{~m} \times 0.25 \mathrm{~mm} \times 0.25 \mu \mathrm{m}$ ) from Phenomenex (Torrance, CA, USA.), each connected to one of the two detectors (MS or FID). The instrument was also equipped with a CombiPAL 2-axis autosampler (CTC Analytics, Zwingen, Switzerland). The carrier was helium at $1.25 \mathrm{~mL} / \mathrm{min}$. Temperature programming was from 50 to $220^{\circ} \mathrm{C}$ at $2{ }^{\circ} \mathrm{C} / \mathrm{min}$, and the temperature of the injector and transfer lines was $250{ }^{\circ} \mathrm{C}$. 
Split flow was $20 \mathrm{ml} / \mathrm{min}$ (split ratio 1:16) and injection volume was $0.4 \mu \mathrm{L}$. All MS analyses were made in the electron impact (EI+) mode at $70 \mathrm{eV}$, the mass range was from 40 to $650 \mathrm{~m} / \mathrm{z}$, and the chromatogram acquired in total ion current (TIC). Compound identification was based on matching the MS spectrum with the NIST14 library and with a self-built EOs/terpenes library, then confirming the identity with Kovat's type retention index [29]. Determination of retention indexes was achieved by injecting in GC-MS under identical settings as the essential oil to a reference mixture of linear alkanes (C6-C32) and processing results with Equation (9), where $\mathrm{n}$ and $\mathrm{N}$ are the number of carbons the linear alkanes were eluting, respectively, just before and just after the unknown compound and the $\mathrm{rt}^{\prime}$ for each compound (unknown or reference alkane) was the measured retention time (rt) corrected by subtracting the rt of an unretained reference.

$$
\text { Kovat's Index }=100\left[n+(N-n) \frac{\log \mathrm{rt}^{\prime}(\text { unknown })-\log \mathrm{rt}^{\prime}(n)}{\log \mathrm{rt}^{\prime}(N)-\log \mathrm{rt}^{\prime}(n)}\right]
$$

Semi-quantitative analysis of each oil was based on the relative $\%$ area of the chromatographic peak over the total area in the chromatogram, by means of 3 repeated injections in GC-FID, under identical settings used for identification in GC-MS. These values were also used to estimate the mass ratio (e.g., the relative concentration in $\mathrm{g} / \mathrm{L}$ ) among the components, assuming an RRF of 1 for all components.

\subsection{Inhibited Autoxidation Studies}

The absolute reactivity of EOs with peroxyl radicals was determined from their kinetics of oxygen consumption during the inhibited autoxidation of cumene or squalene. The reaction was thermally initiated at constant rate $\left(R_{\mathrm{i}}\right.$ in the range $\left.(2-9) \times 10^{-9} \mathrm{Ms}^{-1}\right)$ by the decomposition of AIBN $\left.(1-5) \times 10^{-2} \mathrm{M}\right)$, and the oxygen consumption was measured in a differential oxygen-uptake apparatus developed in our laboratory, based on a Validyne DP15 pressure transducer (Northridge, CA, USA), which has been previously described [45]. Tocopherol's mimic 2,2,5,7,8-pentamethyl-6-chromanol (PMHC) was used as a reference antioxidant $[46,47]$. In a typical experiment, an air-saturated solution of the oxidizable substrate $(50 \% v / v$, corresponding to $3.6 \mathrm{M}$ and $1.04 \mathrm{M}$ for cumene and squalene, respectively) containing $\mathrm{AIBN}(0.05 \mathrm{M})$ in $\mathrm{PhCl}$ (sample) is equilibrated at $30^{\circ} \mathrm{C}$ with an identical reference solution containing an excess of PMHC (25 mM) so as to block any radical chain in the reference and avoid significant consumption of the antioxidant therein during the experiment. After reaching a constant $\mathrm{O}_{2}$ consumption in the sample, a stock solution of the antioxidant in $\mathrm{PhCl}$ was injected in the sample flask. From the slope of the oxygen consumption during the inhibited period, $k_{\text {inh }}$ values were obtained using Equation (7) $[18,40,48-50]$, where $n$ was the stoichiometric coefficient of the antioxidant set as $n=2$ and $k_{\mathrm{p}}$ was the rate constant for chain propagation of the substrate: $k_{\mathrm{p}}$ (in $\mathrm{PhCl}$, $30{ }^{\circ} \mathrm{C}$ ) was $0.34 \mathrm{M}^{-1} \mathrm{~s}^{-1}$ for cumene [16] and $68 \mathrm{M}^{-1} \mathrm{~s}^{-1}$ for squalene [40]. The length of the inhibition period $(\tau)$ was determined graphically as the crosspoint between the initial tangent of the inhibited period and the final tangent of the not-inhibited period; however, in critical cases like curve $\mathbf{e}$ in Figure 2a, a valuable alternative was offered by the integral method described by Loshadkin et al. [51]. In the autoxidations of squalene, where there was no clear inhibited period or the experiment was stopped before its conclusion, kinetic analysis was performed using Equation (10), where $R_{0}$ and $R_{\mathrm{AH}}$ were the rate of oxygen consumption in the absence or presence of the antioxidant, and $2 \mathrm{k}_{\mathrm{t}}$ was the bimolecular termination rate constant (Equation (4)) of cumene or squalene $[15,49,50]$. Values of $2 k_{\mathrm{t}}$ (in $\mathrm{PhCl}, 30^{\circ} \mathrm{C}$ ) were $4.5 \times 10^{4} \mathrm{M}^{-1} \mathrm{~s}^{-1}$ for cumene [16] and $7.4 \times 10^{6} \mathrm{M}^{-1} \mathrm{~s}^{-1}$ for squalene [40]. Measurements were performed at three different concentrations for each EO: $1 \mathrm{mg} / \mathrm{L}, 100 \mathrm{mg} / \mathrm{L}$ and an intermediate concentration in the range $30-50 \mathrm{mg} / \mathrm{L}$ (see Figure S6) to check the validity of Equation (10). Although Equation (10) would best be used by plotting $\left(\mathrm{R}_{0} / R_{\mathrm{AH}}-R_{\mathrm{AH}} / R_{0}\right)$ vs. [AH] and determining $k_{\text {inh }}$ from its slope [49,50], data obtained at $1 \mathrm{mg} / \mathrm{L}$ were discarded form the analysis, as no sizeable inhibition was observed. Hence, the oxygen uptake plots at the remaining two concentrations were directly 
processed by Equation (10) and the results were averaged. The $R_{\mathrm{i}}$ value for any experimental settings was determined in preliminary experiments using PMHC as a reference antioxidant by means of Equation (8).

$$
\frac{R_{0}}{R_{\mathrm{AH}}}-\frac{R_{\mathrm{AH}}}{R_{0}}=\frac{n k_{\mathrm{inh}}[\mathrm{AH}]_{0}}{\sqrt{2 k_{\mathrm{t}} R_{\mathrm{i}}}}
$$

\subsection{Statistical Analysis}

Each measurement was performed in triplicate and results are expressed as mean $\pm \mathrm{SD}$ (standard deviation).

\section{Conclusions}

The five tested EOs of red thyme, oregano, savory, clove bud, and cinnamon contained phenols as the main components: respectively, carvacrol and thymol for the first three and eugenol for the remaining two. Overall, the phenolic content represented 38 to $81 \%$ of the EO. Inhibited autoxidation studies of cumene and squalene indicated that all the tested EOs offered very good protection at a dose that depended on the oxidizability of the substrate. For cumene, full protection was achieved with $1 \mathrm{mg} / \mathrm{L}$ of the EO, while squalene required $100 \mathrm{mg} / \mathrm{L}$ for full protection, corresponding to $0.02 \% w / v$ on the basis of the oxidizable substrate. Kinetic analysis of the oxygen consumption traces matched with GC and GC-MS analysis of the EOs revealed that their antioxidant protection was nearly entirely due to the phenolic components and proportional to their content in the EO. Inhibition rate constants for trapping peroxyl radicals where measured for the first time for these Eos, revealing $k_{\text {inh }}$ values in the order of $1.0 \times 10^{4} \mathrm{M}^{-1} \mathrm{~s}^{-1}\left(30^{\circ} \mathrm{C}\right)$ i.e., of the same magnitude of the widely used BHT, proving on unbiased quantitative grounds that all the tested EOs offer equivalent protection and can replace this synthetic antioxidant, particularly in high-end applications like food products, cosmetics, and pharmaceuticals. These findings call for further studies on a broader range of essential oils.

Supplementary Materials: The following are available online, Figure S1-S5: chromatograms of the essential oils, Tables S1-S5: Tables of compound identification via GC-MS and Kovat's Index, Figure S6: an example of raw oxygen uptake plots in squalene inhibition by oregano EO.

Author Contributions: Conceptualization, L.V.; methodology, R.A. and S.G.; validation, A.B., formal analysis, A.B., S.G. and Y.G.; investigation, Y.G., S.G. and R.P.; resources, L.V. and S.G.; writingoriginal draft, L.V., Y.G. and R.P.; writing—review \& editing, L.V.; supervision, R.A.; project administration, L.V.; funding acquisition, L.V. All authors have read and agreed to the published version of the manuscript.

Funding: This research was funded by the University of Bologna (Italy) RFO2018, and BeC s.r.l. Forlì (Italy); Y.G. acknowledges a fellowship from China Scholarship Council (CSC: 201706790016).

Institutional Review Board Statement: Not applicable.

Informed Consent Statement: Not applicable.

Data Availability Statement: The data presented in this study are available on request from the corresponding author.

Conflicts of Interest: The authors declare no conflict of interest. The funders had no role in the design of the study; in the collection, analyses, or interpretation of data; in the writing of the manuscript, or in the decision to publish the results.

Sample Availability: All compounds are commercially available.

\section{References}

1. Saleh, M.A.; Clark, S.; Woodard, B.; Deolu-Sobogun, S.A. Antioxidant and free radical scavenging activities of essential oils. Ethn. Dis. 2010, 20 (Suppl. S1), 78-82. 
2. Granata, G.; Stracquadanio, S.; Leonardi, M.; Napoli, E.; Malandrino, G.; Cafiso, V.; Stefani, S.; Geraci, C. Oregano and Thyme Essential Oils Encapsulated in Chitosan Nanoparticles as Effective Antimicrobial Agents against Foodborne Pathogens. Molecules 2021, 26, 4055. [CrossRef] [PubMed]

3. Valgimigli, L. (Ed.) Essential Oils as Natural Food Additives: Composition, Applications, Antioxidant and Antimicrobial Properties; Nova Science Publishing: New York, NY, USA, 2012; ISBN 978-1-62100-241-3.

4. Kalemba, D.; Kunicka, A. Antibacterial and antifungal properties of essential oils. Curr. Med. Chem. 2003, 10, 813-829. [CrossRef] [PubMed]

5. Amorati, R.; Foti, M.C.; Valgimigli, L. Antioxidant activity of essential oils. J. Agric. Food Chem. 2013, 61, 10835-10847. [CrossRef] [PubMed]

6. Otoni, C.G.; Pontes, S.F.O.; Medeiros, E.A.A.; Soares, N.D.F. Edible films from methylcellulose and nanoemulsions of clove bud (Syzygium aromaticum) and oregano (Origanum vulgare) essential oils as shelf life extenders for sliced bread. J. Agric. Food Chem. 2014, 62, 5214-5219. [CrossRef]

7. Stea, S.; Beraudi, A.; De Pasquale, D. Essential Oils for Complementary Treatment of Surgical Patients: State of the Art. Evid.-Based Compl. Altern. Med. 2014. [CrossRef]

8. Valdivieso-Ugarte, M.; Gomez-Llorente, C.; Plaza-Díaz, J.; Gil, A. Antimicrobial, Antioxidant, and Immunomodulatory Properties of Essential Oils: A Systematic Review. Nutrients 2019, 11, 2786. [CrossRef]

9. Sadgrove, N.; Jones, G. A Contemporary Introduction to Essential Oils: Chemistry, Bioactivity and Prospects for Australian Agriculture. Agriculture 2015, 5, 48-102. [CrossRef]

10. Hüsnü, K.C.B.; Franz, C. Essential Oils Used in Veterinary Medicine. In Handbook of Essential Oils: Science, Technology, and Applications, 3rd ed.; CRC Press: Boca Raton, FL, USA, 2020; p. 14.

11. Spada, M.; Cuzman, O.A.; Tosini, I.; Galeotti, M.; Sorella, F. Essential oils mixtures as an eco-friendly biocidal solution for a marble statue restoration. Int. Biodeter. Biodegrad. 2021, 163, 105280. [CrossRef]

12. Miguel, M.G. Antioxidant and Anti-Inflammatory Activities of Essential Oils: A Short Review. Molecules 2010, 15, 9252-9287. [CrossRef]

13. do Nascimento, L.D.; Barbosa de Moraes, A.A.; Santana da Costa, K.; Pereira Galúcio, J.M.; Taube, P.S.; Costa, C.M.L.; Cruz, J.N.; de Aguiar Andrade, E.H.; de Faria, L.J.G. Bioactive Natural Compounds and Antioxidant Activity of Essential Oils from Spice Plants: New Findings and Potential Applications. Biomolecules 2020, 10, 988. [CrossRef]

14. Raut, J.S.; Karuppayil, S.M. A status review on the medicinal properties of essential oils. Industrial Crops and Products 2014, 62, 250-264. [CrossRef]

15. Amorati, R.; Valgimigli, L. Methods to measure the antioxidant activity of phytochemicals and plant extracts. J. Agric. Food Chem. 2018, 66, 3324-3329. [CrossRef] [PubMed]

16. Valgimigli, L.; Pratt, D.A. Antioxidants in chemistry and biology. In Encyclopedia of radicals in chemistry, biology and materials; Chatgilialoglu, C., Studer, A., Eds.; Wiley Publishing: Chirchester, UK, 2012; Volume 3, pp. 1623-1677.

17. Li, B.; Pratt, D.A. Methods for determining the efficacy of radical-trapping antioxidants. Free Radic. Biol. Med. 2015, 82, 187-202. [CrossRef]

18. Amorati, R.; Valgimigli, L. Advantages and limitations of common testing methods for antioxidants. Free Radic. Res. 2015, 49, 1-12. [CrossRef] [PubMed]

19. Kykkidou, S.; Giatrakou, V.; Papavergou, A.; Kontominas, M.G.; Savvaidis, I.N. Effect of thyme essential oil and packaging treatments on fresh Mediterranean swordfish fillets during storage at 4 degrees C. Food Chem. 2009, 115, 169-175. [CrossRef]

20. Fasseas, M.K.; Mountzouris, K.C.; Tarantilis, P.A.; Polissiou, M.; Zervas, G. Antioxidant activity in meat treated with oregano and sage essential oils. Food Chem. 2008, 106, 1188-1194. [CrossRef]

21. Harpaz, S.; Glatman, L.; Drabkin, V.; Gelman, A. Effects of herbal essential oils used to extend the shelf life of freshwater-reared asian sea bass fish (Lates calcarifer). J. Food Prot. 2003, 66, 410-417. [CrossRef]

22. Sampaio, B.; Edrada-Ebel, R.; Da Costa, F. Effect of the environment on the secondary metabolic profile of Tithonia diversifolia: A model for environmental metabolomics of plants. Sci Rep. 2016, 6, 29265. [CrossRef]

23. Koşar, M.; Demirci, B.; Demirci, F.; Can Başer, K.H. Effect of maturation on the composition and biological activity of the essential oil of a commercially important satureja species from turkey: Satureja cuneifolia Ten. (Lamiaceae). J. Agric. Food Chem. 2008, 56, 2260-2265. [CrossRef]

24. Tohidi, B.; Rahimmalek, M.; Arzani, A. Essential oil composition, total phenolic, flavonoid contents, and antioxidant activity of Thymus species collected from different regions of Iran. Food Chem. 2017, 220, 153-161. [CrossRef]

25. McGrath, A.J.; Garrett, G.E.; Valgimigli, L.; Pratt, D.A. The redox chemistry of sulfenic acids. J. Am. Chem. Soc. 2010, 132, 16759-16761. [CrossRef]

26. Amorati, R.; Pedulli, G.F.; Pratt, D.A.; Valgimigli, L. TEMPO reacts with oxygen-centered radicals under acidic conditions. Chem. Commun. 2010, 46, 5139-5141. [CrossRef] [PubMed]

27. Amorati, R.; Valgimigli, L.; Dinér, P.; Bakhtiari, K.; Saeedi, M.; Engman, L. Multi-faceted reactivity of alkyltellurophenols towards peroxyl radicals: Catalytic antioxidant versus thiol-depletion effect. Chem. Eur. J. 2013, 19, 7510-7522. [CrossRef] [PubMed]

28. Babushok, V.I.; Linstrom, P.J.; Zenkevich, I.G. Retention Indices for Frequently Reported Compounds of Plant Essential Oils. J. Phys. Chem. Ref. Data 2011, 40, 043101. [CrossRef] 
29. Costa, R.; De Fina, M.R.; Valentino, M.R.; Dugo, P.; Mondello, L. Reliable Identification of Terpenoids and Related Compounds by using Linear Retention Indices Interactively with Mass Spectrometry Search. Nat. Prod. Commun. 2007, 2, 413-418. [CrossRef]

30. Cicchetti, E.; Merle, P.; Chaintreau, A. Quantitation in gas chromatography: Usual practices and performances of a response factor database. Flavour Fragr. J. 2008, 23, 450-459. [CrossRef]

31. Guo, Y.; Baschieri, A.; Amorati, R.; Valgimigli, L. Synergic antioxidant activity of $\gamma$-terpinene with phenols and polyphenols enabled by hydroperoxyl radicals. Food Chem. 2021, 345, 128468. [CrossRef]

32. Lucarini, M.; Pedulli, G.F.; Valgimigli, L. Do Peroxyl Radicals Obey the Principle That Kinetic Solvent Effects on H-Atom Abstraction Are Independent of the Nature of the Abstracting Radical? J. Org. Chem. 1998, 63, 4497-4499. [CrossRef]

33. Foti, M.C.; Ingold, K.U. Mechanism of inhibition of lipid peroxidation by gamma-terpinene, an unusual and potentially useful hydrocarbon antioxidant. J. Agric. Food Chem. 2003, 51, 2758-2765. [CrossRef]

34. Baschieri, A.; Pulvirenti, L.; Muccilli, V.; Amorati, R.; Tringali, C. Chain-breaking antioxidant activity of hydroxylated and methoxylated magnolol derivatives: The role of H-bonds. Org. Biomol. Chem. 2017, 15, 6177-6184. [CrossRef]

35. Kallel, I.; Hadrich, B.; Gargouri, B.; Chaabane, A.; Lassoued, S.; Gdoura, R.; Bayoudh, A.; Messaoud, E.B. Optimization of Cinnamon (Cinnamomum zeylanicum Blume) Essential Oil Extraction: Evaluation of Antioxidant and Antiproliferative Effects. Evid.-Based Compl. Altern. Med. 2019. [CrossRef] [PubMed]

36. Kaur, K.; Kaushal, S.; Rani, R. Chemical Composition, Antioxidant and Antifungal Potential of Clove (Syzygium aromaticum) Essential Oil, its Major Compound and its Derivatives. J. Essent. Oil Bear. Plants 2019, 22, 1195-1217. [CrossRef]

37. Wołosik, K.; Knaś, M.; Zalewska, A.; Niczyporuk, M.; Przystupa, A.W. The importance and perspective of plant-based squalene in cosmetology. J. Cosmet. Sci. 2013, 64, 59-66.

38. Chen, H.; Liu, R.H. Potential Mechanisms of Action of Dietary Phytochemicals for Cancer Prevention by Targeting Cellular Signaling Transduction Pathways. J. Agric. Food Chem. 2018, 66, 3260-3276. [CrossRef] [PubMed]

39. Reddy, L.H.; Couvreur, P. Squalene: A natural triterpene for use in disease management and therapy. Adv. Drug Deliv. Rev. 2009, 61, 1412-1426. [CrossRef]

40. Baschieri, A.; Pizzol, R.; Guo, Y.; Amorati, R.; Valgimigli, L. Calibration of squalene, p-cymene, and sunflower oil as standard oxidizable substrates for quantitative antioxidant testing. J. Agric. Food Chem. 2019, 67, 6902-6910. [CrossRef] [PubMed]

41. Amorati, R.; Zotova, J.; Baschieri, A.; Valgimigli, L. Antioxidant Activity of Magnolol and Honokiol: Kinetic and Mechanistic Investigations of Their Reaction with Peroxyl Radicals. J. Org. Chem. 2015, 80, 10651-10659. [CrossRef]

42. de Saint Laumer, J.-Y.; Cicchetti, E.; Merle, P.; Egger, J.; Chaintreau, A. Quantification in Gas Chromatography: Prediction of Flame Ionization Detector Response Factors from Combustion Enthalpies and Molecular Structures. Anal. Chem. 2010, 82, 6457-6462. [CrossRef]

43. Baschieri, A.; Daci Ajvazi, M.; Folifack Tonfack, J.L.; Valgimigli, L.; Amorati, R. Explaining the antioxidant activity of some common non-phenolic components of essential oils. Food Chem. 2017, 232, 656-663. [CrossRef]

44. Kulisic, T.; Radonic, A.; Mladen Milos, M. Inhibition of lard oxidation by fractions of different essential oils. Grasas y Aceites 2005, 56, 284-291. [CrossRef]

45. Lucarini, M.; Pedulli, G.F.; Valgimigli, L.; Amorati, R.; Minisci, F. Thermochemical and Kinetic Studies of a Bisphenol Antioxidant. J. Org. Chem. 2001, 66, 5456-5462. [CrossRef] [PubMed]

46. Valgimigli, L.; Lucarini, M.; Pedulli, G.F.; Ingold, K.U. Does beta-carotene really protect vitamin E from oxidation? J. Am. Chem. Soc. 1997, 119, 8095-8096. [CrossRef]

47. Haidasz, E.A.; Meng, D.; Amorati, R.; Baschieri, A.; Ingold, K.U.; Valgimigli, L.; Pratt, D.A. Acid Is Key to the Radical-Trapping Antioxidant Activity of Nitroxides. J. Am. Chem. Soc. 2016, 138, 5290-5298. [CrossRef] [PubMed]

48. Johansson, H.; Shanks, D.; Engman, L.; Amorati, R.; Pedulli, G.F.; Valgimigli, L. Long-lasting antioxidant protection: A regenerable BHA analogue. J. Org. Chem. 2010, 75, 7535-7541. [CrossRef] [PubMed]

49. Denisov, E.T.; Azatyan, V.V. Inhibition of Chain Reactions; Gordon and Breach Science Publishing: London, UK, 2000; ISBN 90-6994-002-7.

50. Denisov, E.T.; Afanas'ev, I.B. Oxidation and Antioxidants in Organic Chemistry and Biology; CRC Press: Boca Raton, FL, USA, 2005; ISBN 0-8247-5356-9.

51. Loshadkin, D.; Roginsky, V.; Pliss, E. Substituted p-hydroquinones as a chain-breaking antioxidant during the oxidation of styrene. Int. J. Chem. Kinet. 2002, 34, 162-171. [CrossRef] 